\title{
Influence of the Biocidal Agent Layer on Selected Properties of the Blown Polyethylene Film
}

\author{
Łukasz Majewski', Mariusz Kłonica', Tomasz Jachowicz ${ }^{1 *}$ \\ 1 Lublin University of Technology, Faculty of Mechanical Engineering, ul. Nadbystrzycka 36, 20-618 Lublin, \\ Poland \\ * Corresponding author's e-mail: t.jachowicz@pollub.pl
}

\begin{abstract}
This paper discusses the problems connected with applying a biocidal substance onto the surface of a blown extruded polyethylene film in order to improve the functional properties of the film while maintaining its processing properties unchanged. The objective of the study was to determine the relationship between biocide application method and selected properties of the tube film. Two methods of biocide application onto the film surface were developed: one relied on spraying the biocide onto the hot melt surface directly during the extrusion process, while in the other the biocide was sprayed horizontally onto the blown film after the extrusion process. Biocide distribution uniformity, friction coefficients and surface free energy of the modified film were examined, and the quality and mechanical strength of heat- sealed joints were estimated. In addition, the geometric properties of the blown film were determined.
\end{abstract}

Keywords: blown film extrusion, film modification, surface free energy, sealability, film geometric properties.

\section{INTRODUCTION}

The problems of modifying films such as polyethylene in order to change their properties have been discussed in many studies [6, 27]. New properties were obtained by introducing various types of additives into the film material, such as slips or fillers (including nanofillers) [15, 22, 28], as well as by physical modification of the film surface, e.g. via activating film surface by various methods $[6$, $20,23]$ or changing its geometric structure, e.g. by knurling [19]. Studies were carried out on, among others, the effect of fillers on film strength properties $[24,31]$ and the influence of film activation on its suitability for printing [21]. In addition, factors affecting the coefficient of friction were determined $[29,30]$. Solutions for improving the barrier properties of films were also investigated, as reported in [9, 31]. The latter of the mentioned research problems is particularly important in the production of packaging, including food packaging. Another interesting research area concerns the addition of chemical compounds with biocidal properties into the film or their application onto the film surface. When investigating various methods of film modification, it is necessary to ensure that the processing properties of the film remain unchanged (or decrease insignificantly), because the produced and modified film is often subjected to further processing, predominantly heat sealed or printed, hence the need to ensure that these processes are carried out correctly and efficiently. Improved barrier properties or modified microstructure of the film surface cannot result in e.g. reduced sealability or decreased tribological properties of the film, because at a later production stage this would deteriorate the functional properties of the final product (e.g. a plastic bag), reduce production efficiency or even disturb the production process. These issues are particularly important in terms of mass production, where technological lines are equipped with high-speed packing machines, the effectiveness of which depends on the undisturbed transport of films and high-quality heat sealing [29, 31].

\section{RESEARCH METHODS}

\section{Materials}

In the study we used low-density polyethylene Malen E FABS 23-D022, delivered in pellet 
Table 1. Selected properties of low-density polyethylene Malen E FABS 23-D022 [16]

\begin{tabular}{|l|c|}
\hline \multicolumn{1}{|c|}{ Property } & Value \\
\hline Density & $923 \mathrm{~kg} / \mathrm{m}^{3}$ \\
\hline Melting temperature & $112^{\circ} \mathrm{C}$ \\
\hline $\begin{array}{l}\text { Melt Flow Rate }(\mathrm{MFR}) ; \\
\left(190^{\circ} \mathrm{C} / 2.16 \mathrm{~kg}\right)\end{array}$ & $1.95 \mathrm{~g} / 10 \mathrm{~min}$ \\
\hline Tensile modulus & $250 \mathrm{MPa}$ \\
\hline Tensile stress at yield & $10 \mathrm{MPa}$ \\
\hline Tensile strength $\mathrm{MD}^{*}$ & $18 \mathrm{MPa}$ \\
\hline Tensile strain at break $\mathrm{MD}^{*}$ & $450 \%$ \\
\hline
\end{tabular}

* Film properties tested using $50 \mu \mathrm{m}$ thickness blown film extruded at a melt temperature of $180^{\circ} \mathrm{C}$ and a blow-up ratio of $1: 2.5$.

form and manufactured by Basell Orlen Polyolefins Ltd. (Płock, Poland). According to the technical data sheet provided by the manufacturer, this polyethylene contains antioxidants, antiblock agents and slip. Selected properties of Malen E FABS 23-D022 are given in Table 1.

The film was coated with FOBOS M-4 from LUVENA S.A. (Luboń, Poland), which is delivered in light-yellow pellet form. This biocidal product primarily provides protection against fungi and moulds and contains the following biologically active compounds: disodium tetraborate (2.6 wt. \%), quaternary ammonium compounds, benzyl-C12-C16-alkyldimethyl, chlorides (1.7 wt. \%) and 3-iodo-2-propynyl butylcarbamate $(0.13 \mathrm{wt}$. \%). According to the manufacturer, the product should be used to prepare a 30\% water solution, which is then applied onto the film surface by spraying.

To ensure better affinity between the film surface and the applied solution, 5 wt. $\%$ of a maleic anhydride grafted polyethylenes compatibilizer from Sigma-Aldrich (St. Louis, USA) was added to the low-density polyethylene granulated product. This compatibilizer is typically added to polyethylene to increase adhesion at the interface between hydrophobic PE and hydrophilic modifiers such as fillers or coatings $[3,4,18]$.

\section{Test stand and measuring instruments}

Tests were performed with the use of a W-25/M technological line for blown film extrusion, manufactured by Metalchem (Toruń, Poland). The line consists of a laboratory single screw extruder, a cross extrusion head, an inflating device, a cooling ring, a flattening device, nip rollers, a windup unit with windup roller rotational speed control, and a winder.
The plasticizing system of the extruder has a screw with a diameter of $\mathrm{D}=25 \mathrm{~mm}$ and a working part length of $\mathrm{L}=25 \mathrm{D}$. The screw rotates at a constant speed and the speed cannot be modified. The heating unit of the plasticizing system consists of eight heaters, each with a capacity of $300 \mathrm{~W}$. The heating unit of the plasticizing system is divided into 3 zones, each with a built-in temperature sensor. A plastic melt filter is mounted at the end of the plasticizing system and is in the form of a perforated plate covered with metal lath. The cross head has an annular slot die with an outside diameter of $90 \mathrm{~mm}$ and a slot die width of $0.8 \mathrm{~mm}$. The head heating unit consists of 3 heaters, each with a power of $600 \mathrm{~W}$, and two temperature sensors. The film windup rate can be controlled by adjusting the rotational speed of the windup rollers.

Film geometry was measured with an electronic micrometre and linear rule. Film surface and heat-sealed joint morphology were examined using the Nikon Eclipse LV100ND microscope provided with the DS-U3 camera and NIS-Elements AR 4.20.00 software.

The PGX goniometer (Fibro Systems AB, Switzerland) was used to calculate both surface free energy (SFE) and contact angles. This instrument is particularly suitable for testing the reaction between a liquid and a solid surface of materials such as polymers, metals, films, paper or cardboard. Prior to measurement, the instrument is placed directly on the surface of the tested object.

Heat-sealed joints were made using a $1200 \mathrm{~W}$ resistance heat sealing machine, PSF650. The machine has a $650 \mathrm{~mm}$ long and $8 \mathrm{~mm}$ wide sealing bar coated with a teflon plate to prevent sticking of the melt. The sealing bar pressure is foot controlled. The sealing time can be adjusted in the range from 0.5 to $9 \mathrm{~s}$.

A two-column testing machine, ZwickRoell Z010 (Ulm, Germany) was used to preform strength testing of heat-sealed joints and determine coefficients of friction.

\section{Methods}

The study investigated the following: biocide distribution on the surface of the modified film samples, contact angle and surface free energy of the modified and unmodified film samples, shear strength and peel force of heat-sealed joints made of the two tested film types, and friction coefficients on the surface of the modified and unmodified film samples. The effects of the windup roller 
Table 2. Temperature in individual zones of the plasticizing system

\begin{tabular}{|l|c|}
\hline \multicolumn{1}{|c|}{ Measurement location } & Temperature $\left({ }^{\circ} \mathbf{C}\right)$ \\
\hline Feed zone & 150 \\
\hline Compression zone & 180 \\
\hline Metering zone & 190 \\
\hline Extrusion head I & 165 \\
\hline Extrusion head II & 165 \\
\hline
\end{tabular}

rotational speed and biocide application method on the film geometry were also determined.

The variable factors were the method of applying the biocide onto the film surface and the windup roller rotational speed. The biocidal agent was applied using two methods: it was sprayed either horizontally onto the produced film or vertically onto the surface of the film tube that has left the extrusion head during the blow extrusion process. In the horizontal spray method, the biocide was first applied to one side of the film and after $24 \mathrm{~h}$ - it was also applied to the other side of the film.

The constant factors included the physical and chemical properties of compatibilizer-containing polyethylene, as well as other conditions for manufacturing the tube film and measuring the investigated parameters. The following rotational speeds of the windup rollers were used during the blow extrusion process: $15,20,25,30,35,40 \mathrm{rpm}$.

The disturbing factors included the instability of voltage supplied to the processing machine and measuring instruments, air temperature and humidity of the laboratory rooms and the resulting cooling conditions for the film tube.

Prior to blown film extrusion, a $30 \%$ aqueous solution of the biocidal substance was prepared according to the manufacturer's instructions. The low density polyethylene granulate was mechanically mixed with the compatibilizer granulate and fed into the extruder hopper. The extrusion process was conducted with temperatures listed in Table 2. The temperatures in individual zones were selected based on the material processing data sheet and literature $[5,16,17,26]$.

Different windup roller rotational speeds (V) were used to produce the following sets of film: unmodified (PE), biocide-modified after blow extrusion (PE/B), and biocide-modified directly during the blow extrusion process $(\mathrm{PE} / \mathrm{Be})$.

Width and thickness of individual film types were measured, and longitudinal and transverse tensions were calculated. When determining the longitudinal tension of the horizontally modified film, the thickness of this film was assumed to be the same as that of the unmodified film. The tension ratios were calculated from Eqs. (1) and (2).

$$
R_{t}=\frac{2 b}{\pi d}
$$

where $R_{t}$ is the transverse tension ratio, $b$ is the breadth of the flattened tubular film, $d$ is the diameter of the extrusion die nozzle.

$$
R_{l}=\frac{g_{0}}{g_{1} R_{t}}
$$

where $R_{I}$ is the longitudinal tension ratio, $g_{0}$ is the annular gap width, $g_{1}$ is the film thickness, $R_{t}$ is the transverse tension ratio.

The tubes of both unmodified and modified film were formed into sheets that were used for making heat-sealed joints. The time of current flow through the sealing bar was set equal to $2 \mathrm{~s}$.

Interactions in a solid/liquid/gas system are described by Young's equation (3) [10, 12, 13, 14, 32]. A graphical interpretation of this equation and contact angle measurement method are shown in Fig. 1.

$$
\sigma_{S V}=\sigma_{S L}+\sigma_{L V} \cos \Theta_{V}
$$

where $\sigma_{S V}$ is the surface tension at the solid/gas interface, $\sigma_{S L}$ is the surface tension at the solid/liquid interface, $\sigma_{L V}$ is the surface tension at the liquid/gas interface, $\Theta_{V}$ is the equilibrium contact angle.

The Owens-Wendt method is one of the most widely used methods for calculating the surface free energy of construction materials $[10,11,14$, 32]. According to this method, the surface free energy of a solid is the sum of two parts: dispersive $\gamma_{s}{ }^{\mathrm{d}}$ and polar $\gamma_{s}^{\mathrm{p}}$, these two quantities being described by an additive relationship (4):

$$
\gamma_{s}=\gamma_{s}^{d}+\gamma_{s}^{p}
$$

where $\gamma_{S}$ is the surface free energy of a solid, $\gamma_{S}{ }^{\mathrm{d}}$ is the dispersive part of the surface free energy of the tested materials, $\gamma_{s}^{\mathrm{p}}$ is the polar component of the surface free energy of the tested materials.

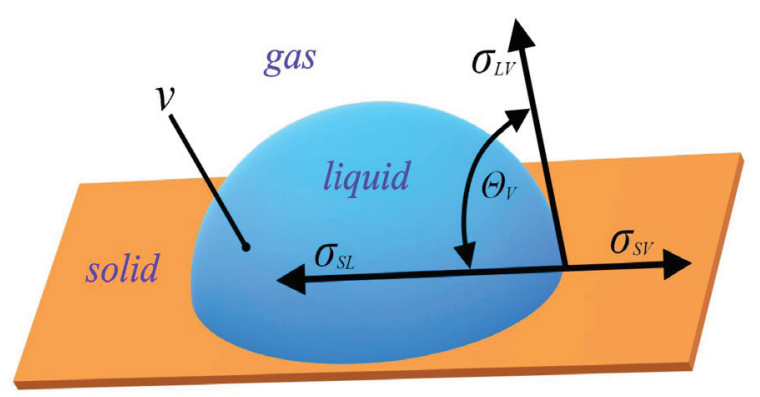

Fig. 1. Graphical interpretation of Young's equation and contact angle measurement method 
Two standard liquids with known SEP values, i.e. distilled water and diiodomethane, were used in the tests in compliance with ASTM D5946 [1]. The liquid with a constant volume of $4 \mu 1$ was applied automatically to the substrate by the PGX goniometer drop applicator. Contact angle measurements using both distilled water and diiodomethane were made at least 10 times per every tested film type. The measurements were made at a temperature of $24^{\circ} \mathrm{C}$ and a relative humidity of about $40 \%$.

The strength tests were performed using 10 $\mathrm{mm}$ wide test samples taken from a film tube with the use of a die cutter, its geometry compliant with the specifications established in the PN-EN ISO 527-1 standard [7]. The tests were carried out in compliance with the ASTM F88 standard [2].

Static and dynamic coefficients of friction were determined in compliance with the ISO 8295 standard [8], using the ZwickRoell Z010 testing machine. The tests were carried out at a feed rate of $100 \mathrm{~mm} / \mathrm{min}$ and an initial force of $0.2 \mathrm{~N}$.

\section{RESULTS AND DISCUSSION}

The biocide was applied to the films immediately above the extrusion head, and the extrusion process was conducted with only two rotational speeds of the windup rollers because at higher speeds the biocidal substance would accumulate on the flattening rollers and thus cause the biocide to flow to the head off the film tube wall, resulting in the breaking of the film tube.

Significant differences can be observed in the appearance of the obtained film tubes. The unmodified film is transparent. The horizontally sprayed film shows the presence of irregularly-shaped white lumps (salt deposits from the biocidal substance) that significantly affect the film transparency. Similar salt deposits can also be observed on the film modified with the biocide sprayed immediately above the extrusion head; however, they are smaller in size and have a more uniform distribution, and thus have a less significant effect on the transparency of this film. The difference in the appearance of the modified films may be due to the fact that the vertically modified film passes through the flattening rollers. The rollers might have contributed to a uniform distribution of the biocide remnants that did not evaporate despite the high temperature of the melt.

Microscopic images show the differences in the appearance of both film types in a more clear way. The salt deposits in the vertically modified film are generally of regular shapes with a gentle edge, some of them are stretched toward the windup rollers (Fig. 2a). The spacing between the salt deposits is usually greater than their size. Apart from the considerable salt deposits ranging from 146 to $498 \mu \mathrm{m}$, much smaller salt deposits can be observed too. The salt deposits on the horizontally modified film are bigger than those observed in the overhead modified film, thus it is difficult to define the upper limit of their size (Fig. 2b). The salt deposits are irregular in shape, with sharp edges. The salt deposits exhibit some kind of crystalline structure. One can also identify areas with separated fragments of the biocidal substance. The separation of the large-size salt deposits may result from their cracking during the passing of the film.

Microscopic images of heat-sealed joints were also captured. A heat seal continuity in the unmodified film is not broken. One can clearly identify the characteristic texture of the fabric left by the

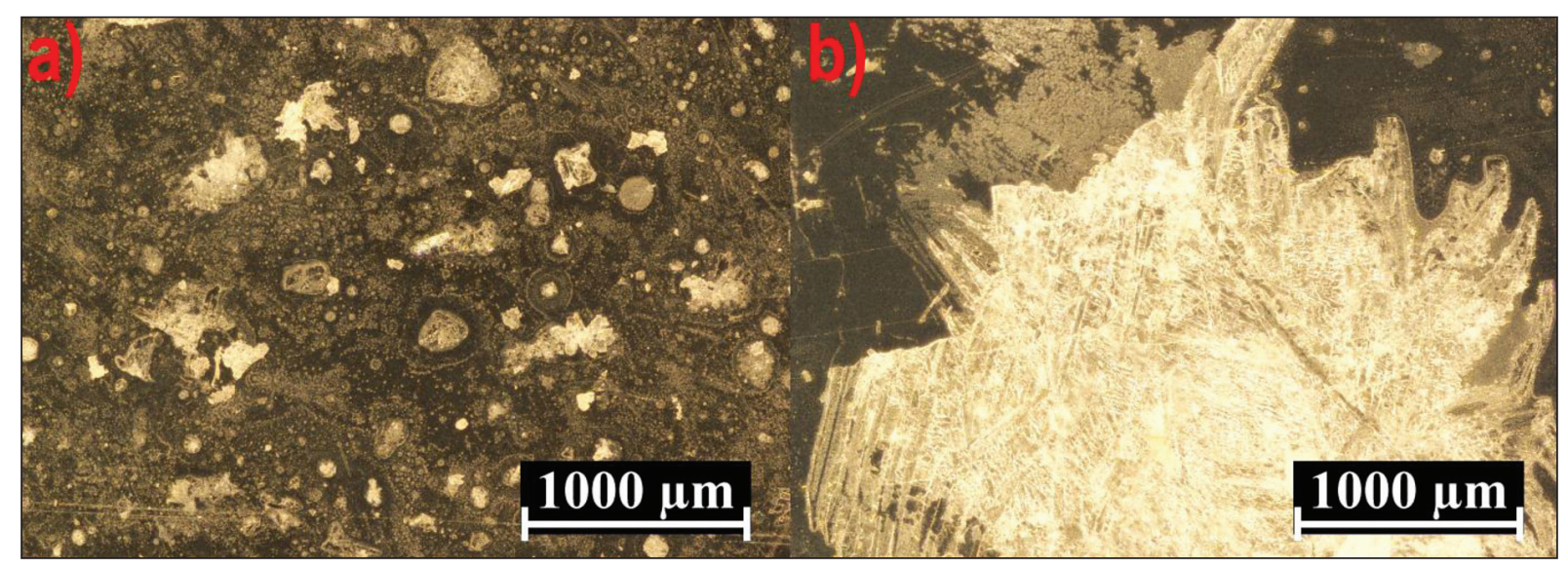

Fig. 2. Microscopic images of film surface: a) PE/Be20; b) PE/B20 


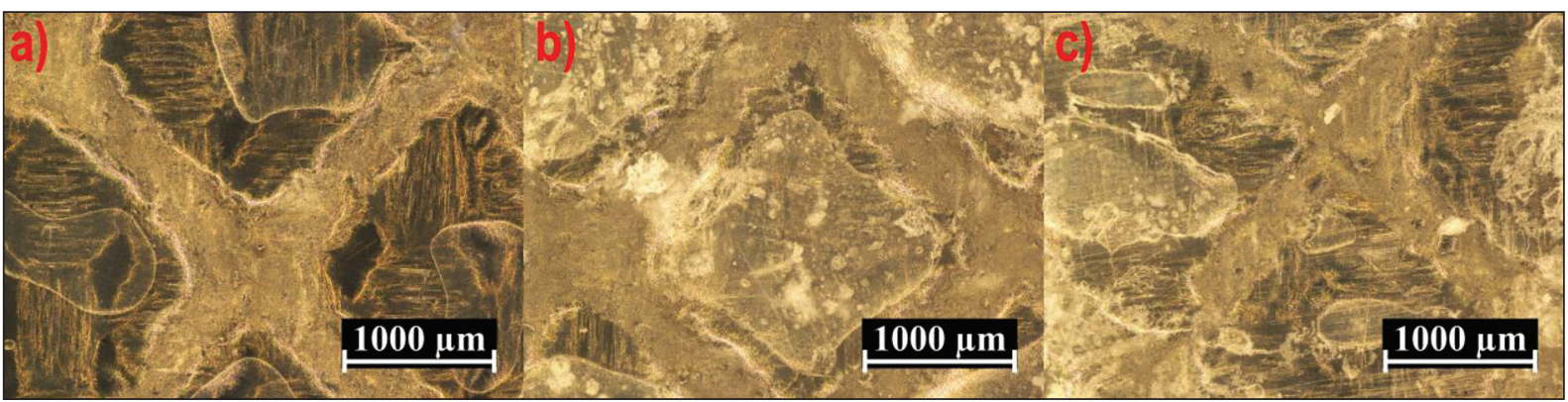

Fig. 3. Microscopic images of heat-sealed films a) PE20, b) PE/Be20, c) PE/B20

sealing machine plates, and tight square cells filled with single air bubbles are formed between the heat seal lines (Fig. 3a). An analysis of the images showing the film sprayed during the extrusion process reveals that the heat seal outline is distorted. Although the heat seal continuity is not broken at any point, the shape of the cells is distorted (Fig. $3 b)$. On the other hand, the film sprayed after the extrusion process (Fig. 3c) shows the presence of clear discontinuities in the heat seal structure, which will significantly affect its strength.

Geometric properties as well as longitudinal and transverse tension ratios depending on the windup roller rotational speed for individual films are given in Tables 3, 4 and 5. The longitudinal and transverse tension ratios of the $\mathrm{PE} / \mathrm{B}$ film were calculated based on the pre-spray data because the subsequent change in its thickness results from the presence of the biocide rather than the phenomena occurring during the extrusion process. Therefore, the longitudinal and transverse tensile ratios of this film samples are similar.

The relationship observed between the windup roller rotational speed and the film thickness is obvious and typical of low-density polyethylene [32]. An interesting observation can be made regarding the relationship between the biocide application method and the film thickness. The highest film thickness is observed for the film samples sprayed with the biocide in a horizontal manner. The use of this film modification method yields the highest deviation from the average film

Table 3. Average values of the geometric properties of PE samples, including standard deviations for all tested windup roller rotational speeds

\begin{tabular}{|c|c|c|c|c|c|c|}
\hline $\begin{array}{c}\mathbf{V} \\
(\mathbf{r e v} / \mathbf{m i n})\end{array}$ & $\begin{array}{c}\mathbf{g}_{1} \\
(\mathbf{m m})\end{array}$ & $\begin{array}{c}\mathbf{s}_{\mathbf{g} 1} \\
(\mathbf{m m})\end{array}$ & $\begin{array}{c}\mathbf{b} \\
(\mathbf{m m})\end{array}$ & $\begin{array}{c}\mathbf{s}_{\mathbf{b}} \\
(\mathbf{m m})\end{array}$ & $\mathbf{R}_{\mathbf{t}}$ & $\mathbf{R}_{\mathbf{1}}$ \\
\hline 15 & 0.063 & 0.0033 & 257 & 0.16330 & 1.82 & 6.96 \\
\hline 20 & 0.046 & 0.0056 & 255.67 & 0.04714 & 1.81 & 9.71 \\
\hline 25 & 0.035 & 0.0044 & 250.33 & 0.04714 & 1.77 & 13.03 \\
\hline 30 & 0.033 & 0.0024 & 248.33 & 0.12472 & 1.76 & 13.79 \\
\hline 35 & 0.027 & 0.0026 & 253.67 & 0.04714 & 1.80 & 16.44 \\
\hline 40 & 0.025 & 0.0023 & 253 & 0.08165 & 1.79 & 17.71 \\
\hline
\end{tabular}

Table 4. Average values of the geometric properties of PE/B samples, including standard deviations for all tested windup roller rotational speeds

\begin{tabular}{|c|c|c|c|c|c|c|}
\hline $\begin{array}{c}\mathbf{V} \\
(\mathbf{r e v} / \mathbf{m i n})\end{array}$ & $\begin{array}{c}\mathbf{g}_{\mathbf{1}} \\
(\mathbf{m m})\end{array}$ & $\begin{array}{c}\mathbf{s}_{\mathbf{g 1}} \\
(\mathbf{m m})\end{array}$ & $\begin{array}{c}\mathbf{b} \\
(\mathbf{m m})\end{array}$ & $\begin{array}{c}\mathbf{s}_{\mathbf{b}} \\
(\mathbf{m m})\end{array}$ & $\mathbf{R}_{\mathbf{t}}$ & $\mathbf{R}_{\mathbf{1}}$ \\
\hline 15 & 0.087 & 0.0056 & 255 & 0.08168 & 1.80 & 7.01 \\
\hline 20 & 0.078 & 0.0124 & 255.33 & 0.04714 & 1.81 & 9.72 \\
\hline 25 & 0.067 & 0.0130 & 253.67 & 0.12472 & 1.80 & 12.85 \\
\hline 30 & 0.055 & 0.0107 & 253.33 & 0.12472 & 1.80 & 13.52 \\
\hline 35 & 0.053 & 0.0132 & 251.67 & 0.12742 & 1.79 & 16.57 \\
\hline 40 & 0.048 & 0.0124 & 251.33 & 0.09428 & 1.78 & 17.83 \\
\hline
\end{tabular}


Table 5. Average values of the geometric properties of PE/Be samples, including standard deviations for all tested windup roller rotational speeds

\begin{tabular}{|c|c|c|c|c|c|c|}
\hline $\begin{array}{c}\mathbf{V} \\
(\mathbf{r e v} / \mathbf{m i n})\end{array}$ & $\begin{array}{c}\mathbf{g}_{\mathbf{1}} \\
(\mathbf{m m})\end{array}$ & $\begin{array}{c}\mathbf{s}_{\mathbf{g} 1} \\
(\mathbf{m m})\end{array}$ & $\begin{array}{c}\mathbf{b} \\
(\mathbf{m m})\end{array}$ & $\begin{array}{c}\mathbf{s}_{\mathbf{b}} \\
(\mathbf{m m})\end{array}$ & $\mathbf{R}_{\mathbf{t}}$ & $\mathbf{R}_{\mathbf{l}}$ \\
\hline 15 & 0.076 & 0.0037 & 240.33 & 0.18856 & 1.70 & 6.16 \\
\hline 20 & 0.057 & 0.0052 & 244.33 & 0.04714 & 1.73 & 8.02 \\
\hline
\end{tabular}

thickness for the tested speeds. This means that the biocide applied horizontally has a non-uniform distribution and that the film surface repeatability is low with this application method.

The longitudinal and transverse tension ratios of the PE/Be samples are lower than those of the unmodified film samples. Every tube of the film (modified and unmodified) was inflated with air until it came into contact with the restraining bars for maintaining constant tube width and transverse tension ratio. The biocide sprayed onto the film has a room temperature, which is much lower than the temperature of the extruded film. This fact could have contributed to the reduction in the values of the aforementioned ratios because the film was cooled much earlier than under standard conditions, which led to faster crystallization of the melt.

Fig. 4 shows the relationship between the heat seal shear strength and the windup roller rotational speed determined for individual film types. As previously shown in Tables A, B and C, the rotational speed of the windup rollers has impact on the thickness of the heat-sealed film.
An analysis of the data in Fig. 4 demonstrates that the average heat seal shear strength of the biocide-modified film is lower than that of the unmodified film. This decrease is particularly visible in the case of the film samples that become thinner due to increasing the windup roller rotational speed from 30 to $40 \mathrm{rpm}$. The heat seal shear strength has decreased from about $8 \mathrm{MPa}$ to nearly $4 \mathrm{MPa}$, i.e. almost twofold. To give an example, the heat seal shear strength of the film produced at $40 \mathrm{rpm}$ is $4.68 \mathrm{MPa}$, while the shear strength of the same unmodified film is $8.63 \mathrm{MPa}$. Therefore, the decrease in the heat seal strength in the case under analysis amounts to $84.2 \%$. With thicker films produced at the windup roller rotational speeds ranging from 15 to $25 \mathrm{rpm}$, the shear strength decrease is not so significant -the heat seal shear strength of the unmodified film is in the range of 6.5 to $7 \mathrm{MPa}$ while that of the modified film ranges from $4.48 \mathrm{MPa}$ to $5.12 \mathrm{MPa}$, i.e. the decrease is about $40 \%$.

In the range of windup roller rotational speed from 15 to $20 \mathrm{rpm}$, the film modified directly during the blow extrusion process $(\mathrm{PE} / \mathrm{Be})$ shows a

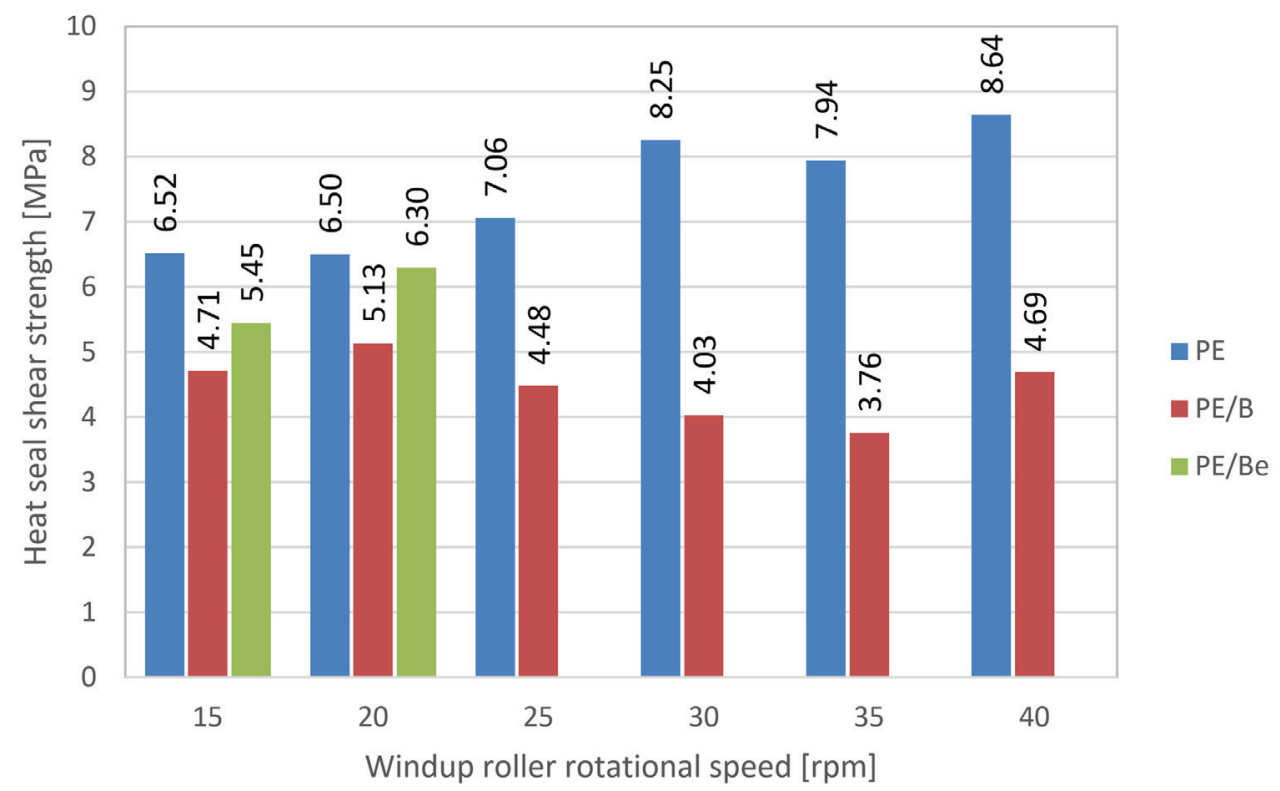

Fig. 4. Heat seal shear strength versus windup roller rotational speed 


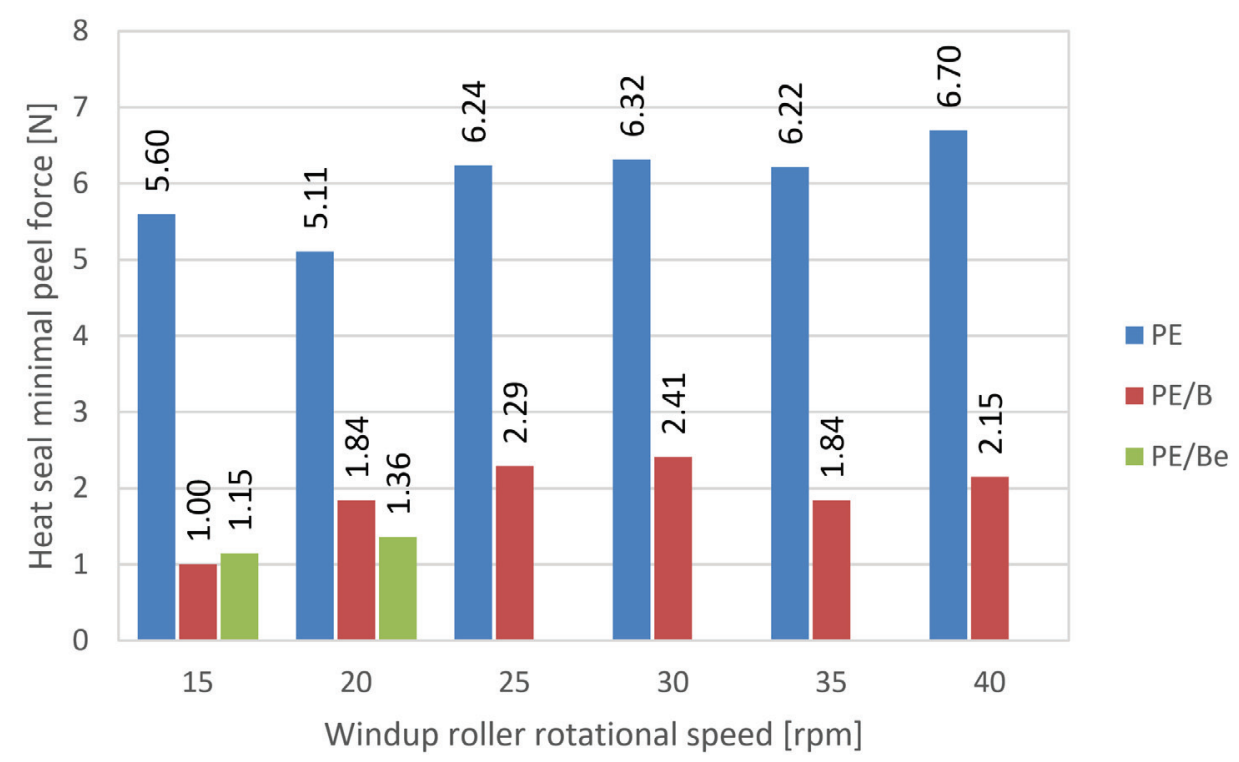

Fig. 5. Heat seal minimal peel force versus windup roller rotational speed

decrease in the heat seal shear strength. However, this decrease is several times lower than in the case of the film samples that were modified after the blow extrusion process. For the PE/Be film produced at $15 \mathrm{rpm}$ this decrease is slightly over $19 \%$, while in the case of the $\mathrm{PE} / \mathrm{Be}$ samples produced at $20 \mathrm{rpm}$ the decrease in the heat seal shear strength is only $3 \%$.

It can also be observed that the heat seal shear strength is higher in the film samples that were under higher tension (and therefore had lower thickness) than in the thicker film samples. This may indicate that the heat sealing parameters were incorrect, particularly that the heat sealing temperature was too low for the thicker films.

Similarly to the shear strength test, the presence of the biocidal substance reduces the peel force of the modified film samples compared to the unmodified film samples. This relationship is plotted in Figure 5. The reduction in this mechanical strength indicator of the heat seal is even more considerable than the decrease observed with respect to its shear strength. This is most clearly visible in the case of the film produced at the windup roller rotational speed of $15 \mathrm{rpm}$, when the peel force is reduced by $458 \%$. The smallest observed decrease in the minimal peel force amounts to $161 \%$ and concerns the films produced at the windup roller rotational speed of $30 \mathrm{rpm}$. Regarding the effect of the biocide application method, no clear trend can be observed because the film modified with the biocide directly during the film tube production at the speed of $15 \mathrm{rpm}$ has a slightly higher peel force, whereas at the speed of $20 \mathrm{rpm}$ the minimal peel force is higher for the film modified after the extrusion process and lower for the film modified directly during the extrusion process.

Figures 6 and 7 show the results of static and dynamic friction coefficients. In all analysed cases, as expected, the obtained static friction coefficients are higher than the dynamic friction coefficients. It should however be noted that the PE/B samples are characterized by a small difference between the static and dynamic friction coefficients. For the speed of $40 \mathrm{rpm}$ this difference is $16.2 \%$, but for the speed of $20 \mathrm{rpm}$ the static and dynamic friction coefficients are almost the same. The PE/Be film modified during blow extrusion has higher coefficients of friction than the unmodified film due to the fact that its surface is more developed. Nevertheless, the friction coefficients of the $\mathrm{PE} / \mathrm{Be}$ samples are significantly lower than those of the PE/B film. The windup roller rotational speed has the greatest influence on the friction coefficients of the PE film samples. The static friction coefficient increases with increasing the speed, and the difference between its values obtained with $20 \mathrm{rpm}$ and $40 \mathrm{rpm}$ amounts to $220 \%$. This is probably caused by a higher cooling rate and a higher degree of crystallinity due to more intensive crystallite nucleation [25].

The results demonstrate that the addition of the biocide has impact on the contact angles of the tested measuring liquids (Fig. 8). It is found that the biocide addition has a greater effect 
on the distilled water contact angle. The average distilled water contact angle of the PE20 samples is about $88^{\circ}$, while that of the $\mathrm{PE} / \mathrm{B} 30$ samples is about $18^{\circ}$, which makes it about 5 times lower. It is worth pointing to good reproducibility of the contact angle results for both distilled water and diiodomethane. This indicates a uniform energy state of the entire analysed surface layer of the films. The observation is particularly important for further processing, such as printing or labelling.

Figure 9 shows the relationship between film surface layer modification and surface free energy (SFE). The results demonstrate that the biocide addition has a significant effect on the surface free energy of the films. The surface free energy is $45 \mathrm{~mJ} / \mathrm{m}^{2}$ for the PE samples, $52 \mathrm{~mJ} / \mathrm{m}^{2}$ for the $\mathrm{PE} / \mathrm{Be} 20$ samples, and about $76 \mathrm{~mJ} / \mathrm{m}^{2}$ for the $\mathrm{PE} / \mathrm{B}$ samples. The highest increase in the SFE value can be observed for the PE/B30 samples - compared to the PE20 samples, their SFE has increased by about $75 \%$. It is worth stressing the increase in the polar part of SFE, because this part is responsible for the adhesive properties of the film. The highest increase in the polar part of SFE can be observed for the PE/B samples - compared to the PE sample, their polar SFE has increased sevenfold.

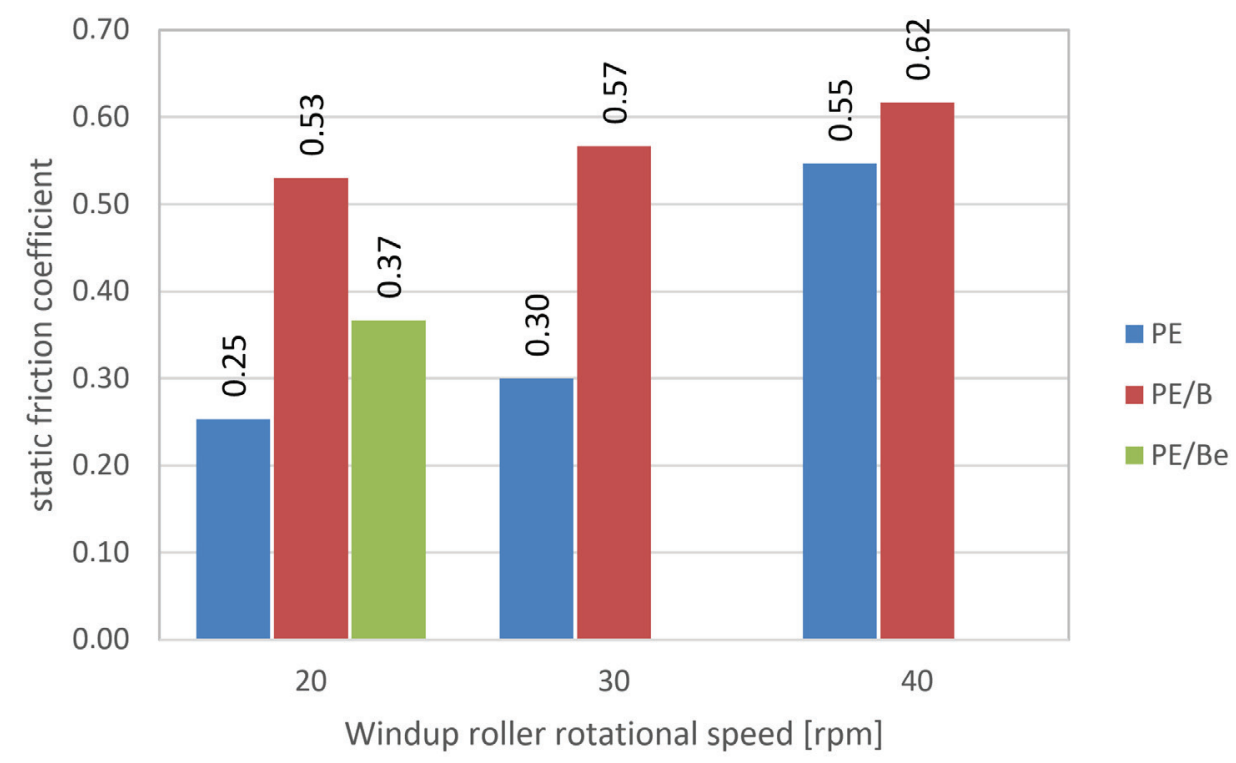

Fig. 6. Static friction coefficient versus windup roller rotational speed

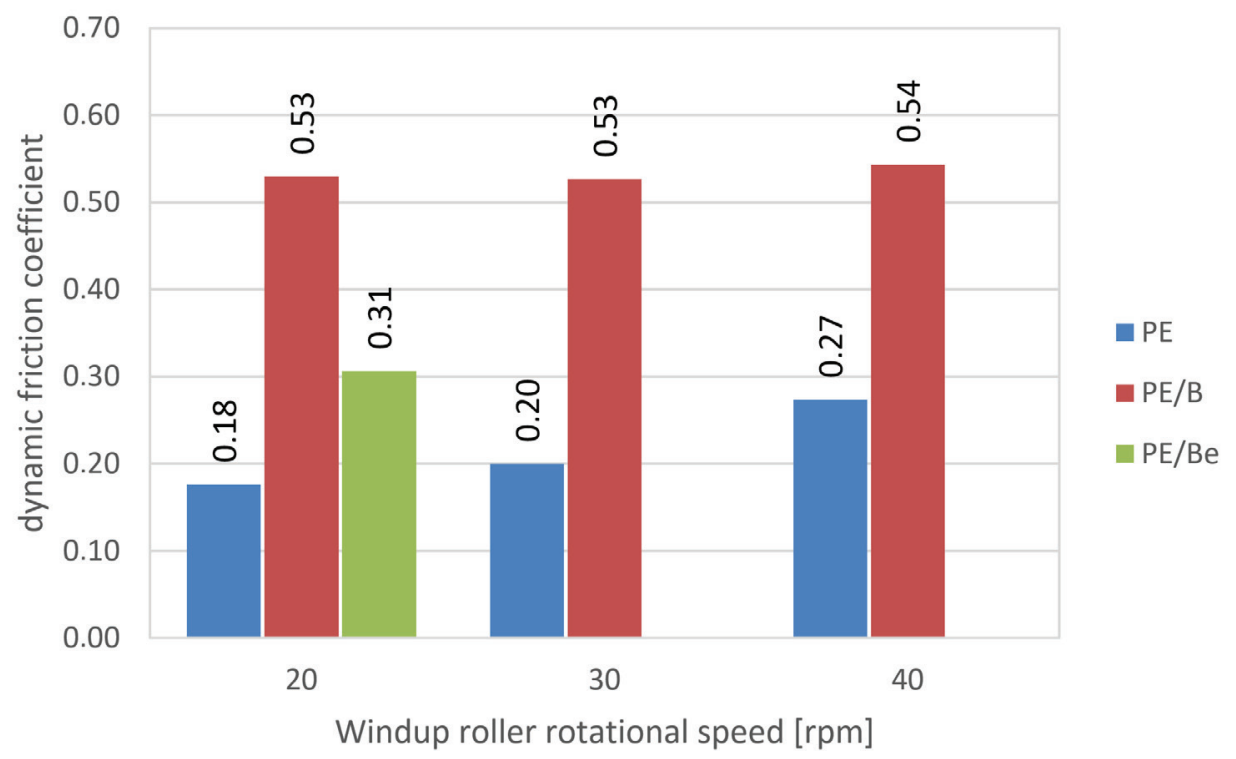

Fig. 7. Dynamic friction coefficient versus windup roller rotational speed 


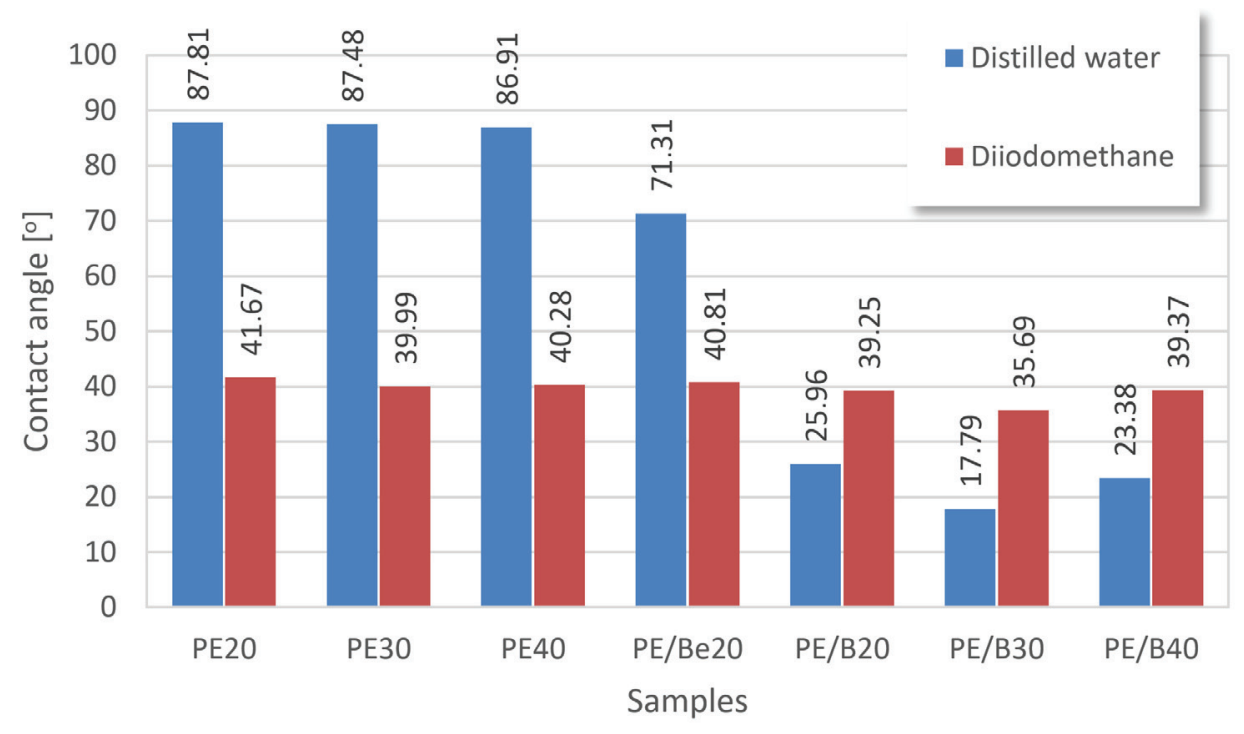

Fig. 8. Surface layer modification versus contact angle

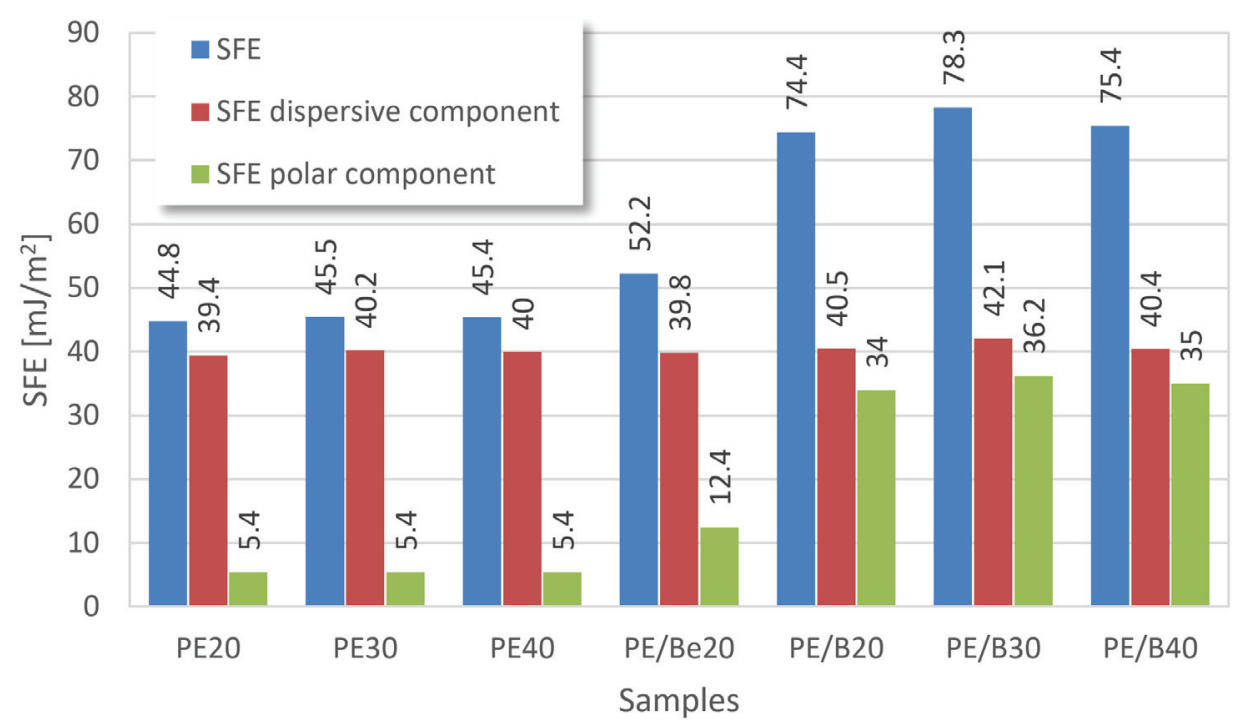

Fig. 9. Surface layer modification versus SEP

\section{CONCLUSIONS}

The results of this study have clearly demonstrated that the addition of the biocide affects both unmodified and modified polyethylene film with respect to geometry, contact angle and surface free energy, heat seal shear strength and minimal peel force.

An increase in the windup roller rotational speed caused a decrease in the PE film thickness from $63 \mu \mathrm{m}$ to $25 \mu \mathrm{m}$. Moreover, it has been shown that the application of the biocide onto the film surface during the blow extrusion process leads to a higher thickness of this film compared to the unmodified film. This results from faster cooling of the film tube and thus its limited tension in the longitudinal and transverse directions.

The addition of the biocide has led to an increase in the surface free energy of the tested films, which is extremely important from the point of view of further processing such as printing, painting, varnishing or labelling. The highest increase in SFE has been observed for the PE/B30 samples $\left(\mathrm{SFE}=78.3 \mathrm{~mJ} / \mathrm{m}^{2}\right)$; compared to the results obtained for the PE20 samples (SFE $=44.8$ $\mathrm{mJ} / \mathrm{m}^{2}$ ), the SFE of the PE/B30 film has increased by approx. $75 \%$. The results have revealed that the polar part of SEP increases too, which is of 
vital importance regarding adhesive properties of materials. The highest, sevenfold increase in the polar part of SFE has been observed for the PE/B samples, when compared to the PE samples.

The application of the biocide onto the polyethylene film surface has resulted in a significant decrease in the quality of the heat-sealed joint, primarily in terms of its mechanical strength. Both the heat seal shear strength and the minimal peel force are several times lower in the biocidecoated film samples. In the extreme case, the decrease in strength is almost fivefold (458\%), and it concerns the decrease in the minimal peel force of the film samples modified with the biocide after the blow extrusion process, produced at the lowest tested windup roller rotational speed of 15 $\mathrm{rpm}$. The application of the biocide reduces the functional properties of the heat-sealed joint. Taking into account the previously mentioned problems with applying the biocide onto the hot surface of the film during the blow extrusion process, it seems reasonable that with higher rotational speeds of the windup rollers the biocide should be applied by spraying onto the finished product obtained from the film tube after the heat sealing operation. On the other hand, the high values of the friction coefficients may suggest serious difficulties with separating and moving individual layers of the film sprayed after the extrusion process, which may potentially prevent its use in automatic packaging machines.

The observed two- or threefold decrease in the strength properties of the heat seal made by the resistance method and the substantial increase in the friction coefficients indicate that that it is ineffective to apply the biocide onto the film tube surface both during the blow extrusion process and after it, when the tube is already cooled and flattened by the windup rollers.

\section{Acknowledgements}

The project/research was financed in the framework of the project Lublin University of Technology - Regional Excellence Initiative, funded by the Polish Ministry of Science and Higher Education (contract no. 030/RID/2018/19).

\section{REFERENCES}

1. ASTM D5946-17 - Standard test method for corona-treated polymer films using water contact angle measurements.
2. ASTM F88 - Standard test method for seal strength of flexible barrier materials.

3. Biswas K., Khandelwal S., Maiti S. N.: Mechanical and thermal properties of teak wood flour/starch filled high density polyethylene composites. International Polymer Processing, 34, 2019, 209-218.

4. Ghosh S. K., Das T. K., Ghosh S., Ganguly S., Nath K., Das N. C.: Physico-mechanical, rheological and gas barrier properties of organoclay and inorganic phyllosilicate reinforced thermoplastic films. Journal of Applied Polymer Science, 2020, https://doi. org/10.1002/app.49735.

5. Glowik-Lazarczyk K., Jurczyk S., Chmielnicki B., Konieczny J., Labisz K.: Influence of oxo-degradable $\mathrm{PE}$ recyclate addition on the degradation of commercial low density polyethylene (PE-LD). Journal of Environmental Protection and Ecology, 2017, 18, 947-961.

6. Goddard J. M., Hotchkiss J. H.: Rechargeable Antimicrobial Surface Modification of Polyethylene. Journal of Food Protection 2008, 71, 10, 2042-2047. DOI: https://doi.org/10.4315/0362028X-71.10.2042.

7. ISO 527-1:2019 - Plastics - Determination of tensile properties - Part 1: General principles.

8. ISO 8295 - Plastics - Film and sheeting - Determination of the coefficients of friction.

9. Jacquelot E., Espuche E., Gérard J. F., Duchet J., Mazabraud P.: Morphology and gas barrier properties of polyethylene-based nanocomposites. Journal of Polymer Science Part B: Polymer Physics 2005, 44, 2. DOI: https://doi.org/10.1002/polb.20707.

10. Jańczuk B., Białopiotrowicz T., Zdziennicka A.: Some remarks on the components of the liquid surface free energy. Journal of Colloid and Interface Science, 1999, 211, 96-103.

11. Kłonica M.; Kuczmaszewski J. Determining the value of surface free energy on the basis of the contact angle. Advances in Science and Technology Research Journal 2017, 11 (1), 66-74, https:// doi.org/10.12913/22998624/68800.

12. Kłonica M.; Kuczmaszewski J.; Kwiatkowski M.; Ozonek J. Polyamide 6 surface layer following ozone treatment. International Journal of Adhesion and Adhesives 2016, 64, 179-187, https://doi. org/10.1016/j.ijadhadh.2015.10.017.

13. Kubit A., Trzepiecinski T., Kłonica M., Hebda M., Pytel M.: The influence of temperature gradient thermal shock cycles on the interlaminar shear strength of fibre metal laminate composite determined by the short beam test. Composites Part B 176 (2019) 107217.

14. Kuczmaszewski J.: Fundamentals of metal-metal adhesive joint design. Politechnika Lubelska. Oddział PAN w Lublinie. Lublin, 2006. 
15. Llop C., Manrique A., Navarro R., Mijangos C., Reinecke H.: Control of the migration behavior of slip agents in polyolefin-based films. Polymer Engineering \& ScienceVolume 2011, 51, 9. DOI: https://doi.org/10.1002/pen.21963.

16. Malen E FABS 23-D022 - material data sheet: https://basellorlen.pl/wp-content/uploads/2020/08/ ML_E_FABS_23_D022_TDS_2020_02_05 rev_9_EN.pdf. Access: 09.10.2020.

17. Merkel K., Lenża J., Rydarowski H., Pawlak A., Wrzalik R.: Characterization of structure and properties of polymer films made from blends of polyethylene with poly(4-methyl-1-pentene). Journal of Materials Research, 2017, 32, 451-464.

18. Nasiri A., Gastaldi E., Gontard N., Peyron S.: Multi-faceted migration In food contact polyethylene-based nanocomposite packaging. Applied Clay Science, 2020, 198. Article ID 105803.

19. Noori H., Jain M., Nielsen K., Brandys F.: Influence of metallic substrate surface engineering on peel resistance of adhesively bonded polymer film. Journal of Adhesion Science and Technology 2015, 29, 13, 1403-1413. DOI: https://doi.org/10.1080/01 694243.2015.1031442.

20. Novák I., Pollák V., Chodák I.: Study of Surface Properties of Polyolefins Modified by Corona Discharge Plasma. Plasma Processes and Polymers 2006, 3, 4-5. DOI: https://doi.org/10.1002/ppap.200500163.

21. Ramirez J. C. C., Tumolva T. P.: Analysis and optimization of water-based printing ink formulations for polyethylene films. Applied Adhesion Science 2018, 6, 1. https://doi.org/10.1186/s40563-017-0102-z.

22. Rezić I., Haramina T., Rezić T.: Metal nanoparticles and carbon nanotubes - perfect antimicrobial nanofillers in polymer-based food packaging materials. Food Packaging 2017, 497-532. DOI: https://doi. org/10.1016/B978-0-12-804302-8.00015-7.

23. Sadeghnejada A., Aroujalianab A., Raisiab A., Fazelab S.: Antibacterial nano silver coating on the surface of polyethylene films using corona discharge. Surface and Coatings Technology, 2014, 245, 1-8. DOI: https://doi.org/10.1016/j.surfcoat.2014.02.023.

24. Seungran Yoo, Holloman C., Tomasko D., Koelling K., Pascall M. A.: Effect of High Pressure Processing on the Thermal and Mechanical Properties of Polyethylene Films Measured by Dynamical Mechanical and Tensile Analyses. Packaging Tech- nology and Science 2013, 27, 3. DOI: https://doi. org/10.1002/pts.2021.

25. Sheeja M. O.; Juraij K., Sneha S. P., Ashitha K., Aleena L.S., Sujith A.: Polyethylene-g-Starch Nanoparticle Biocomposites: Physicochemical Properties and Biodegradation Studies. Polymer Composites, 2018, 39, S1, E426-E440.

26. Sikora, J., Majewski Ł., Puszka, A.: Modern biodegradable plastics - processing and properties: part I. Materials, 2020, 13, 1986.

27. Srinivasa Kartik Nemani, Rama Kishore Annavarapu, Behrouz Mohammadian, Asif Raiyan, Jamie Heil, Mohammad Ashraful Haque, Ahmed Abdelaal, Hossein Sojoudi: Surface Modification of Polymers: Methods and Applications. Advanced Materials Interfaces 2018, 5, 24. DOI: https://doi. org/10.1002/admi.201801247.

28. Suberlyak O., Krasinskyi V., Moravskyi V., Gerlach H., Jachowicz T.: Influence of aluminosilicate filler on the physicomechanical properties of polypropylene-polycaproamide composites. Materials Science 2014, 50, 2, 296-302. DOI: https://doi. org/10.1007/s11003-014-9721-8.

29. Suresh, B., Maruthamuthu, S., Kannan, M. et al.: Mechanical and surface properties of low-density polyethylene film modified by photo-oxidation. Polymer Journal 2011, 43, 398-406. DOI: https:// doi.org/10.1038/pj.2010.147.

30. Suresh, B., Maruthamuthu, S., Khare, A. et al.: Influence of thermal oxidation on surface and thermo-mechanical properties of polyethylene. Journal of Polymer Research 2011, 18, 2175-2184. DOI: https://doi.org/10.1007/s10965-011-9628-0.

31. Yang Zhong, Janes D., Yong Zheng, Hetzer M., De Kee D.: Mechanical and oxygen barrier properties of organoclay-polyethylene nanocomposite films. Polymer Engineering \& Science 2007, 47, 7. DOI: https://doi.org/10.1002/pen.20792.

32. Zhang X. M., Elkoun S., Ajji A., Huneault M. A.: Oriented structure and anisotropy properties of polymer blown films: HDPE, LLDPE and LDPE. Polymer, 2004, 45, 217-229.

33. Żenkiewicz M.: New method of analysis of the surface free energy of polymeric materials calculated with Owens-Wendt and Neumann methods. Polimery 2006, 51, 584-587. M3. 